\title{
Invasive Prenatal Diagnosis: Amniocentesis
}

\author{
${ }^{1}$ Mariana Theodora, ${ }^{2}$ Panos Antsaklis, ${ }^{3}$ Aris Antsaklis
}

\begin{abstract}
In this article, we will review the history and the evolution of the technique of amniocentesis and the indications of the most common invasive diagnostic and therapeutic procedure. Moreover, the most common complications of amniocentesis will be presented. Finally, we will try to establish if the use of concurrent ultrasound had any effect on the prevalence on these complications.
\end{abstract}

Keywords: Amniocentesis, Invasive prenatal diagnosis.

How to cite this article: Theodora M, Antsaklis $\mathrm{P}$, Antsaklis A. Invasive Prenatal Diagnosis: Amniocentesis. Donald School J Ultrasound Obstet Gynecol 2015;9(3):307-313.

Source of support: Nil

Conflict of interest: None

\section{HISTORY OF THE PROCEDURE}

Amniocentesis is the first invasive procedure used in fetal medicine for both prenatal diagnosis and therapy. Although amniotic fluid withdrawal has been practiced for more than 150 years, the first reported cases of transabdominal evacuative amniocentesis were those of Prochownick et al in 1877, Schatz in $1882^{1}$ and Hinkel in 1919 describing release of amniotic fluid from a patients with polyhydramnios. Menees et $\mathrm{al}^{2}$ reported removal of amniotic fluid by transabdominal needling using a radio-opaque contrast to outline the fetus and placenta.

At the beginning of the $1950 \mathrm{~s}^{3}$, it was used to determine the amniotic composition in cases of Rhesus isoimmunization and to correlate it with the severity of the condition of the newborn. Later on, Liley ${ }^{4}$ published the well-known correlation between the deviation of the spectral absorption curve of amniotic fluid resulting from bilirubin and the severity of rhesus isoimmunization. Since Liley's studies, the practice of amniocentesis in pregnancies complicated by Rhesus disease was the standard procedure in obstetric practice until Mary described the use of middle cerebral artery (MCA) peak velocity in predicting fetal anemia and the need for in-utero blood transfusion in a noninvasive way.

\footnotetext{
1-31st Department of Obstetrics and Gynecology, Department of Fetal Maternal Medicine, Alexandra Maternity Hospital University of Athens, Athens, Greece

Corresponding Author: Marianna Theodora, 1st Department of Obstetrics and Gynecology, Department of Fetal Maternal Medicine Alexandra Maternity Hospital, University of Athens, Vas Sofias 80 Athens 11527, Greece, e-mail: m.theodora@praksis.gr
}

Amniocentesis was used for diagnostic reasons in the $50 \mathrm{~s}$, as a method for sex determination by the identification of Barr bodies in the noncultured amniocytes. ${ }^{5}$ About 10 years later, Steele and Breg reported in their paper in Lancet that the karyotype of the embryo was determined through an amniotic fluid cell culture. ${ }^{6}$ During the same year Thiede et al published similar findings later. The first case of prenatal diagnosis of Trisomy 21 (Down syndrome) was reported in 1968 by Nadler. In 1970, Nadler and Gerbie published the 'Role of amniocentesis in the intrauterine diagnosis of genetic defects' in the New England Journal of Medicine. This article was an innovation concerning genetic amniocentesis and diagnosis and since then genetic laboratories for analysis of amniotic fluid had become prevalent and indications for genetic amniocentesis included the detection of chromosomal abnormalities, gene disorders, X-linked conditions, inborn errors of metabolism, and the neural tube defects.

Amniocentesis has been established as a basic invasive method for the prenatal diagnosis of various pregnancy related conditions, such as fetal karyotyping, diagnosis of metabolic or enzymatic diseases, assessment of the severity hemolytic disease, establishment of lung maturity, diagnosis of fetal infections. Additionally, amniocentesis is used for the infusion of various drugs into the amniotic cavity, determination of the composition of the amniotic fluid and finally for evacuation of hydramnion.

\section{EVOLUTION OF THE TECHNIQUE}

During the 30s removal of amniotic was done by transabdominal needling following injection of a radio-opaque contrast in order to outline the fetus and placenta. (Menees et al reported in 1930). Later on amniocenteses were performed 'blindly' and the puncture site located merely by external palpation of the uterus in the abdomen. In 1967, Hofmann and Hollander in Germany stated the importance of placental localization using ultrasound before amniocentesis. Amniocentesis under ultrasound guidance was started to be implemented in 1972, with reports from Bang and Northeved from Hans Hendrik Holm at the Gentofe Hospital in Copenhagen. In the mid 1970s to mid 80s, amniocentesis was performed with the assistance of a static or realtime B-scan. A scan was first performed to locate a feasible pocket of amniotic 
fluid before a tap, the skin on top of that area was marked and the puncture was done without actually seeing the needle tip going into the fluid pocket.

Improvement of ultrasound real time scanners in the late 1970s, a small number of centers started to perform amniocentesis with the simultaneous visualization of the puncture needle tip on the scanner monitor. One such pioneer was the Birnholz group at Harvard who used an early phased array for the purpose. Needleguide adapters soon became available from ultrasound manufacturers which could be coupled to the linear array or phased array sector probes where the needle passed through a fixed path either parallel or at an angle to the ultrasonic beam. These were difficult to use, however, particularly in a busy setting. They also had serious problem of keeping the equipment sterile. The adapters may also increase the risk of traumatization as it did not allow for the 'desired' and sensitive placement of needles.

Many centers started to do a freehand technique with an assistant holding onto the transducer probe that was commonly wrapped in a sterile adhesive drape. In 1984, Holzgreve in Basel, Switzerland described a large series of over 3000 'freehand' amniocenteses with low complication rate. Similar experience was also reported by Platt in Los Angeles, who emphasized on the need for the transducer probe to be manipulated by the same operator which resulted in better hand-eye co-ordination. In the following year, Romero ${ }^{7}$ formally described the single operator two-hands technique in amniocentesis and the reduction in the number of multiple taps and bloody taps associated with the procedure. Most centers soon adopted the single operator technique, which had become popular because of its convenience and effectiveness. Newer needles were marketed with special external coating and echoluminance to enhance needle placement. Complication rates were reportedly lower with each successive improvement in technique.

\section{INDICATIONS}

Amniocentesis is used for both prenatal diagnosis and fetal therapy. In Table 1, we summarize the main indications for amniocentesis.

\section{COMPLICATIONS OF AMNIOCENTESIS}

During amniocentesis, the fetomaternal unit is injured, and thus a number of complications may occur. Maternal complications are rare. They include perforation of the intra-abdominal viscera with subsequent intra-abdominal infection, sepsis, bleeding, blood group sensitization and uterine contractions. ${ }^{8}$ The use of ultrasound guidance during amniocentesis has minimized the risk of maternal
Table 1: Indications for amniocentesis

Chromosome analysis
1. Advanced maternal age
2. Abnormal biochemical screening in 1st or 2 nd trimester
3. Ultrasound findings (major and minor markers)
4. Family or personal history of chromosomal abnormalities in
previous preganancies
5. Abnormal parental karyotype
6. Maternal anxiety
DNA analysis
1. Genetic testing
2. Endocrine disorders
Suspected fetal anemia
1. Rhesus sensitization
2. Fetal hydrops
Fetal Infection (PCR for CMV, Parvovirus,
Toxoplasma Gondii etc.)
Lung maturity
Chorioamnionitis (diagnosis of possible infection)
Biochemistry
Obstetric cholestasis
Fetal therapy

injury. Also aseptic technique and the use of anti-D immunoglobulin has eliminated the risk of maternal sepsis and rhesus sensitization.

Fetal complications, though, are the main concern. They include fetal loss, placental abruption, preterm labor and preterm rupture of membranes. Needle puncture injuries of the fetus and injury due to withdrawal of amniotic fluid (e.g. amniotic bands) were rare especially since amniocentesis is being performed under ultrasound guidance. Amniocentesis may also cause intra-amniotic infections through the introduction of microorganisms into the amniotic cavity via the needle. In order to eliminate the possibility of an infectious complication, rules of asepsic procedures which apply in all surgical procedures must be applied during amniocentesis, such as the aseptic cleaning of the skin and using sterilized medical gloves and needles. However, endometrial infections are not always related to amniocentesis, but may exist before the prenatal intervention. ${ }^{9,10}$

\section{FETAL LOSS}

Fetal loss is the ultimate risk of genetic amniocentesis. When amniocentesis was first introduced in the clinical practice the risk of miscarriage due to the procedure could not be estimated accurately because there was lack of ultrasound guidance and lack of determination of fetal viability before the procedure.

Since fetal miscarriage does not occur only in association with amniocentesis, the background loss rate which is associated with the gestation age, parity and any other underlying risk factors is important to be 
determined before estimating the procedure loss rate. For instance gestational age at the procedure is an important determinant of the observed fetal loss rate, since the earlier the pregnancy the greater is the pre-procedure risk of miscarriage.

The risk of fetal loss after amniocentesis has been evaluated by several series from single centers and a number of multicenter studies. The controversial results of these studies merely imply the difficulties in evaluating the procedure related loss rate and the changes in practice of the procedure.

In 1976, the National Institute of Child Health and Human Development (NICHD) published a case-control, cohort study to evaluate the safety and accuracy of second trimester amniocentesis for prenatal diagnosis. The authors reported that the group who underwent amniocentesis had a $3.5 \%$ total loss rate while the controls had 3.2\%. ${ }^{8}$ The authors of this study also reported that the procedure loss risk was unrelated to previous pregnancy loss, volume of aspirated fluid or the number of attempts.

During the same year, the Canadian Collaborative Study presented an descriptive paper in which the total loss rate after amniocentesis was $3.2 \% .{ }^{11}$ In this study, an increased risk of loss was reported in cases of failed attempts and large bore needles ( $>19$ gauge). The third collaborative case control study was reported by the British Working Party on Amniocentesis in $1978 .{ }^{12}$ The authors concluded that the risk for fetal loss after amniocentesis was $1.2 \%$. This risk was estimated since the total fetal loss before 28 weeks was $2.4 \%$ in cases which underwent amniocentesis and $1.2 \%$ in cases whithout amniocentesis (controls). This study, however, was strongly criticized mainly on the selection of control individuals who were recruited in the study later in gestation and on the replacement of some of the matched controls who had aborted.

The only randomized trial for the estimation of miscarriage risk related to amniocentesis was done in Denmark in $1986 .{ }^{13}$ This study randomized 4,606 low-risk women aged 24 to 35 years to have or not to have an amniocentesis, which was carried out using a 20-gauge needle under real-time ultrasound guidance. Most procedures were performed between 16 and 18 weeks of gestation. The amniocentesis group had a loss rate which exceeded the control group by $1 \%(1.7 \%$ and $0.7 \%$ respectively), a figure which has often been used in counseling couples undergoing amniocentesis. This study has also been criticized due to the very low loss rate in the controls. ${ }^{14}$

Since then a lot of studies reported amniocentesis related fetal loss rate between 0.2 to $0.9 \%{ }^{15-22}$

In 2001, JW Seeds performed a systematic review of 29 controlled and uncontrolled studies with a total of
68.119 amniocenteses. ${ }^{14}$ In this review, Seeds included both reports that described amniocentesis with only preprocedure ultrasound and reports which described amniocentesis with concurrent use of ultrasound guidance.

The goal of this review study was to estimate the procedure-related risk of pregnancy loss after mid trimester amniocentesis. The impact of concurrent ultrasound guidance on this fetal loss and fetal injuries were also examined.

He concluded that amniocentesis with concurrent ultrasound guidance in controlled studies appears to be associated with a procedure-related rate of excess pregnancy loss of $0.6 \%$ (95\% CI, 0.31, 0.90).

When comparing all studies, the risk of pregnancy loss after the procedure and before 28 weeks was eliminated with the use of concurrent real time ultrasound. When only controlled studies were included this trend remained although not significant.

In 2006, Eddleman et al in order to quantify the procedure-related loss rate after midtrimester amniocentesis a database generated from patients who were recruited to the first and second trimester evaluation of risk for aneuploidy (FASTER) trial was used. ${ }^{23}$ A total of 35,003 unselected patients from the general population with viable singleton pregnancies were enrolled in this trial and 3.096 of them underwent midtrimester amniocentesis. The total spontaneous fetal loss rate less than 24 weeks of gestation in the study group was $1.0 \%$ and was not statistically different from the background $0.94 \%$ rate seen in the control group $(\mathrm{P}-0.74,95 \%$ $\mathrm{Cl}-0.26 \%, 0.49 \%)$. The researchers stated that the odds of pregnancy loss were actually lower in patients who underwent amniocentesis because of advanced maternal age or screen positive results compared with those who did not. They concluded that this is likely due to the fact that spontaneous pregnancy loss is so strongly associated with aneuploidy, and patients who have an amniocentesis would presumably terminate aneuploid fetuses in most cases before a spontaneous loss could occur. They stated that it is not surprising that patients in these categories who elected not to undergo amniocentesis, had a higher rate of spontaneous loss because they were carrying a higher proportion of aneuploid fetuses.

Mujezinovic F and Alfirevic $Z$ reviewed a number of studies in order to provide data for counseling concerning complications after amniocentesis and chorionic villus sampling (CVS). ${ }^{24}$ Twenty-nine articles of amniocentesis were included. Total pregnancy loss within 14 days was estimated to be $0.6 \%$ [95\% confidence interval (CI) 0.5-0.7], rising to $0.9 \%$ (95\% CI 0.6-1.3) for pregnancy loss before 24 weeks and $1.9 \%$ (95\% CI 1.4-2.5) for total pregnancy loss. However, the authors noted that since most of the reviewed studies do not take into account the background 
risk and, therefore, do not address the issue of added, procedure-related risk, these figures may be useful only for counseling purposes in a broad sense. The authors included in their review only five studies which have control groups in order to quantify the background risk. Overall, these studies reported higher pregnancy losses compared with uncontrolled case series and the pooled results showed a relative increase of $25 \%$ for total pregnancy loss after amniocentesis and $46 \%$ for pregnancy losses before 24 or 28 weeks gestation. The results for the latter were heterogeneous, resulting in very wide, statistically no significant confidence intervals. The absolute risk difference between cases and controls was quite similar, showing that second trimester pregnancy loss and total fetal loss after an amniocentesis increase by approximately $0.6 \%$. The reviewers noted that although the risk of pregnancy loss is relatively low, lack of adequate controls tends to underestimate the true added risk of prenatal invasive procedures.

Since then more smaller controlled and uncontrolled studies has been published reporting significantly smaller risks for fetal loss..$^{25,26}$

In our department, we have preformed a retrospective controlled study in order to estimate the fetal loss rate after second trimester amniocentesis.

We recovered from our database 13,220 pregnant women who sought invasive prenatal diagnosis during the second trimester for various indications between the years 1996 and 2010. Complete follow-up was achieved in 12,413 cases $(94 \%)$ and this comprised this study group. Our control group consisted of 6,993 low risk for aneuploidies (less than 1:250) pregnant women who did not have invasive prenatal testing and came to our department for ultrasonographic evaluation between 16th and 20th week of pregnancy. Total fetal loss before the 24th week in the amniocentesis group, having excluded terminations, was $1.25 \%$. Total fetal loss rate up to 24 weeks in the controls was $0.62 \%$ (95\% CI, $0 \%-1.49 \%)$ (Fisher's exact test, $\mathrm{p}=0.444$ ). So, the procedure related loss rate was estimated at $0.6 \%$ and it was not statistically significant different between the study and the control group (data accepted for publication).

It is also known that fetal loss is not associated only with amniocentesis. A number of underlying factor and pathological condition may increase the risk of losing a pregnancy regardless invasive procedures.

For example, history of miscarriages or medical terminations of pregnancies may be responsible for a higher risk of fetal loss even before any procedure. ${ }^{15,27}$

In the same way maternal age and abnormal maternal serum a fetoprotein measurements increase the risk for pregnancy loss. ${ }^{19,28-31}$
Vaginal bleeding during current pregnancy increase the risk of spontaneous abortion and pregnancy loss after amniocentesis in most of the series. ${ }^{29}$ In our recent series, we also found that bleeding during first and early second trimester of current pregnancy increase the risk of pregnancy loss after amniocentesis by two to three times.

Finally, factors associated with the procedure itself may alter the risk after amniocentesis. The number of needle placements, the aspiration of bloody fluid, and especially the observation of green or murky fluid are seen to be associated with a significantly increased risk of pregnancy loss after amniocentesis. 15,27,32,33,37

The number of needle insertions and bloody fluid are related directly to procedure technique, whereas murky or green fluid is not. Murky of green fluid is usually the result of previous intra-amniotic hemorrhage and this is the reason why it is definitely increasing the risk of fetal loss after amniocentesis.

In our series, when the aspirated amniotic fluid was found to be green or brownish blood-stained indicating an old intra-amniotic hemorrhage, the risk of fetal loss is almost six times higher. On the contrary, in cases where amniotic fluid was mixed with fresh blood [e.g. in cases of placenta perforation (Fig. 1)] the fetal loss was not higher than cases when clear amniotic fluid was aspirated. Additionally, the risk of fetal loss is increased when more than one needle insertion in needed although the difference was not statistically significant.

Transplacental needle placement (Fig. 2) was found by some authors, but not others, to be associated with an increased risk of pregnancy loss. ${ }^{13,32,34-37}$

The use of concurrent ultrasound help the operator to reduce the number of needle insertions, reduce bloody amniotic fluid by avoiding placenta insertion (Fig. 3) and aspiration and avoid fibromas. ${ }^{14}$ In this way it may have played a role in reducing the risk of fetal loss after amniocentesis.

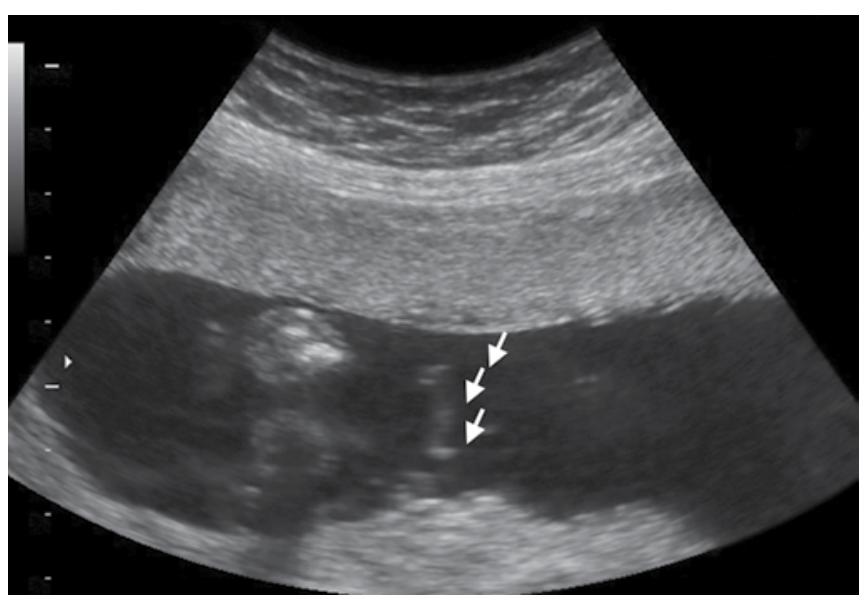

Fig. 1: Intra-amniotic bleeding after placental perforation (transplacental amniocentesis) 
Invasive Prenatal Diagnosis: Amniocentesis

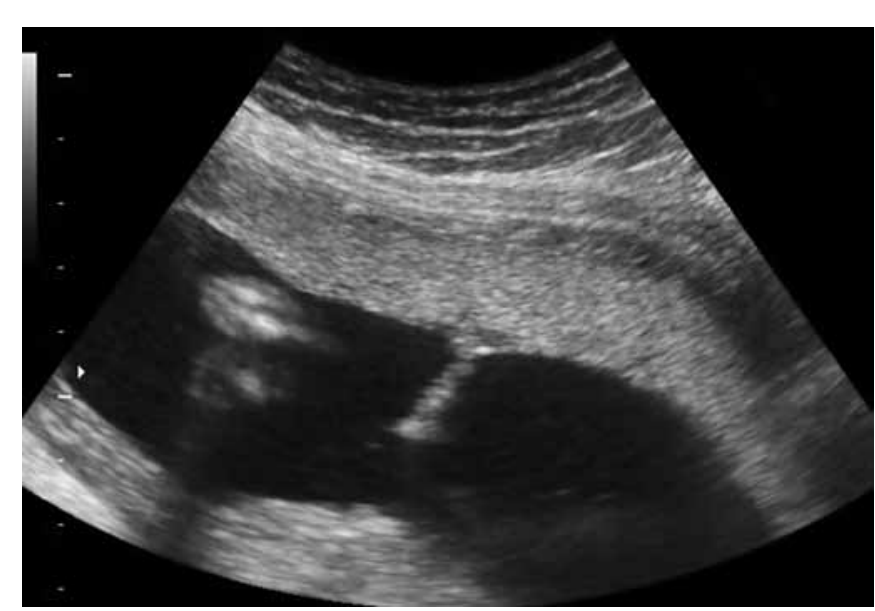

Fig. 2: Transplacental amniocentesis

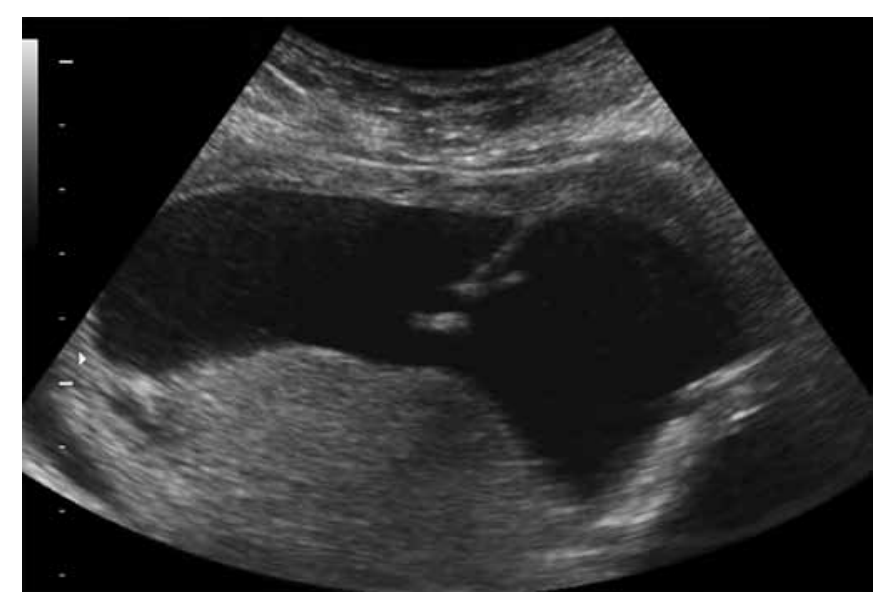

Fig. 3: Transamniotic amniocentesis

\section{PRETERM DELIVERY}

The association of second trimester amniocentesis and delivery before 37 weeks was evaluated by a case control study in 2003 by the EUROPOP Group. ${ }^{38}$ Three thousand and ninety-one preterm births and 5,298 controls randomly selected from singleton births born at term during 1994 to 1997 were analyzed. An increased risk of preterm delivery was found in women having second trimester genetic amniocentesis after taking into account other risk factors and confounding variables (odds ratios (OR 1:59, 95\% confidence intervals (95\% CI): 1.31-1.92). The association was statistically significant and similar for spontaneous preterm delivery and induced preterm delivery.

On the contrary, other studies ${ }^{13,39}$ have shown no difference in the rate of preterm delivery after amniocentesis.

In our study, we also estimated the prevalence of preterm delivery in both study and control group in order to evaluate any added risk of prematurity following second trimester amniocentesis. The percentage of preterm deliveries less that 37 weeks was $10.3 \%$ for the amniocentesis group and $9.1 \%$ for the control group, this difference was not statistically significant $(p=0.223)$.

\section{FETAL TRAUMA}

Theoretically, the risk of direct fetal needle injury should be reduced with the use of simultaneous ultrasound guidance. Nevertheless several case reports document or describe cases of fetal injury to the amniocentesis needle, despite the use of simultaneous guidance for the procedure. ${ }^{40-51}$ This association though is not based on direct evidence. In addition, there are reports of fetal skin marks in cases without amniocentesis and these suggest that these marks may not be the result of needle puncture of the fetus. ${ }^{52}$

\section{ALLOIMMUNIZATION AND VIRAL DISEASE TRANSMISSION}

Fetomaternal hemorrhage occurs in approximately $50 \%$ of all women ${ }^{53}$ and during amniocentesis on one out of six. ${ }^{54}$ The attributed risk is $1 \%$ greater than the background risk of $1.5 \%{ }^{55}$ As for preventing the Rhesus sensitization of the mother and when the husband is Rhesus positive, every Rhesus negative mother must be given $300 \mu \mathrm{g}$ anti-D Immunoglobulin after amniocentesis, provided of course the indirect Coombs is negative. ${ }^{56,57}$

Other means to minimize the risk is the use of small gauge needles and to avoid transplacental approach. ${ }^{57}$

In the same way, HIV and hepatitis virus positive pregnant women are safe to undergo amniocentesis provided that viral load of patients is low and the transplacental route is avoided. ${ }^{58}$

The use of real time ultrasound guidance during the procedure helps the operator to avoid the transplacental route which is crucial in cases of Rhesus negative mothers and HIV or hepatitis virus positive pregnant women.

\section{CONCLUSION}

Real time ultrasound guidance during amniocentesis has reduced the number of needle insertion and the aspiration of bloody amniotic fluid. It has also reduced the cases of placental puncture which although does not associate with increased risk of pregnancy loss, it increases the risk of Rhesus sensitization and transmition of viral diseases (HIV, Hepatitis) for mother to the fetus.

Using concurrent ultrasound guidance seems to decrease the risk of fetal loss after amniocentesis although this decrease is not statistically significant in all series. Finally, the risk of direct fetal trauma is also eliminated when real time ultrasound is used during the needle insertion. 


\section{REFERENCES}

1. Von Schatz F. Gine besondere art von einseitiger polyhydramnie mit anderseitiger oligohydramnie bie eineiigen zwillingen. Arch Gynaecol 1882;19:329.

2. Menees T, Millar JD, Holly LE. Amniography. Preliminary report. Am J Roentgenol 1930;24:353-366.

3. Bevis DCA. The composition of liquor amnii in haemolytic disease of the newborn. J Obstet Gynaecol Br Emp 1953;60: 244-251.

4. Liley AW. Liquor amnii analysis in management of pregnancy complicated by rhesus sensitization. Am J Obstet Gynecol 1961;82:1359-1370.

5. Fuchs F, Riis P. Antenatal sex determination. Nature 1956; 177:330.

6. Steele MW, Breg WR. Chromosome analysis of human amniotic fluid cells. Lancet 1966;1:383.

7. Romero R, Jeanty P, Reece EA, Grannum P, Bracken M, Berkowitz R, et al. Sonographically monitored amniocentesis to decrease intraoperative complications. Obstet Gynecol 1985;65:426-430.

8. National Institute of Child Health and Human Development National Registry for amniocentesis study group: Mid trimester amniocentesis for prenatal diagnosis: safety and accuracy. J Am Med Assoc 1976;236:1471.

9. Cassell GH, Davis RO, Waiter KB, et al. Isolation of mycoplasma hominis and ureaplasma urealyticum from amniotic fluid at 16-20 weeks of gestation: potential effect on outcome of pregnancy. Sex Transm Dis 1983;10:294.

10. Gray DJ, Robinson H, Malone J, et al. Adverse outcome in pregnancy following amniotic fluid isolation of ureaplasma urealyticum. Prenat Diagn 1992;12:111-117.

11. Simpson NE, Dallaire L, Miller JR, et al. Prenatal diagnosis of genetic disease in Canada: report of a collaborative study. Canadian Medical Association Journal 1976;115:739-748.

12. Medical Research Council. An assessment of the hazards of amniocentesis. Br J Obstetr Gynecol 1978;85(Suppl 2):1-41.

13. Tabor A, Philip J, Madsen M, Bang J, Obel EB, NorgaardPedersen B. Randomised controlled trial of genetic amniocentesis in 4606 low-risk women. Lancet 1986;1:1287-1293.

14. John W Seeds. Diagnostic mid trimester amniocentesis: How safe? Am J Obstet and Gynec 2004;191:608-616.

15. Antsaklis A, Papantoniou N, Xygakis A, Mesogitis S, Tzortzis E, Michalas S. Genetic amniocentesis in women 20-34 years old: associated risks. Prenat Diagn 2000;20:247-250.

16. Borrelli AL, Cobellis L, Di Domenico A, Felicetti M, Laboccetta A, Ferrara C, et al. Fetal and maternal amniocentesis complications [in Italian]. Minerva Ginecol 2006;58:423-427.

17. Gaudry P, Grange G, Lebbar A, Choiset A, Girard S, GoffinetF, Lewin F. Fetal loss after Amniocentesis in a series of 5,780 precedures. Fetal Diang Ther 2008;23:217-221.

18. Caughey AB, Hopkins LM, Norton ME. Chorionic villus sampling compared with amniocentesis and the difference in the rate of pregnancy loss. Obstet Gynecol 2006;108:612-616.

19. Papantoniou N, Daskalakis G, Tziotis J, Kitmirides S, Mesogitis, Antsaklis A. Risk factors predisposing to fetal loss following a second trimester amniocentesis BJOG 2001; 108:1053-1056.

20. Sant-Cassia LJ, MacPherson MB, Tyack AJ. Midtrimester amniocentesis: is it safe? A single centre controlled prospective study of 517 consecutive amniocentesis. Br J Obstet Gynaecol 1984;91(8):736-744.
21. Sirichotiyakul S, Yampochai A. Amniocentesis-related fetal loss: a cohort study. Obstet Gynecol 1998;92:64-67.

22. Turhan NO, Eren U, Seckin NC. Second-trimester genetic amniocentesis: 5-year experience. Arch Gynecol Obstet 2005; 271:19-21.

23. Eddleman KA, Malone FD, Sullivan L, Dukes K, Berkowitz RL, Kharbutli Y, et al. Pregnancy loss rates after midtrimester amniocentesis. (FASTER Trial Research Consortium) Obstet Gynecol 2006;108:1067-1072.

24. Mujezinovic F. Alfirevic Z. Procedure-related complications of amniocentesis and chorionic villous sampling: a systematic review. Obstet Gynecol 2007;110:687-694.

25. Odibo AO, Gray DL, Dicke JM, Stamilo DM, Macones GA, Crane JP. Revisiting the fetal loss rate after second-trimester genetic amniocentesis: a single center's 16-year experience. Obstet Gynecol 2008;111:589-595.

26. Tabor A, Vestergaard CHF, Lidegaard O. Fetal loss rate after chorionic villus sampling and amniocentesis: an 11-year national registry study. Ultrasound Obstet Gynecol 2009;34:19-24.

27. Andreasen E, Kristoffersen K. Incidence of spontaneous abortion after amniocentesis: influence of placental localization and past obstetric and gyneoolkoppcologic history. Am J Perinatol 1989;6:268-273.

28. Alfirevic Z. Who should perform amniocentesis and Chorionic villus sampling? (opinion) Ultrasound Obstet Gynecol 2009;34:12-13.

29. Kozlowski P, Knippel A, Stressig R. Individual risk of fetal loss following routine second trimester amniocentesis: a controlled study of 20,460 cases. Ultraschall Med 2008 Apr;29(2):165-172.

30. Mazza V, Pati M, Bertucci E, Re C, Ranzi A, Percesepe A, Forabosco A, Volpe A. Age-specific risk of fetal loss post second trimester amniocentesis: analysis of 5043 cases. Prenat Diagn 2007 Feb;27(2):180-183.

31. Tabor A, Alfirevic Z. Update on precedure-related risks for prenatal diagnosis Techniques. Fetal Diagn Ther 2010;27:1-7.

32. Hanson FW, Tennant FR, Zorn E, Samuels S. Analysis of 2136 genetic amniocenteses: experience of a single physician. Am J Obstet Gynecol 1985;152:436-443.

33. Dacus JV, Wilroy RS, Summitt R, Garbaciak JA, Abdella TN, Spinnato JA. Genetic amniocentesis: a twelve years' experience. Am J Med Genet 1985;20:443-452.

34. Bombard AT, Powers JF, Carter S, Schwartz A, Nitowsky HM. Procedure-related fetal losses in transplacental versus nontransplacental genetic amniocentesis. Am J Obstet Gynecol 1995;172:868-872.

35. Marthin T, Liedgren S, Hammar M. Transplacental needle passage and other risk-factors associated with second trimester amniocentesis. Acta Obstet Gynecol Scand 1997;76:728-732.

36. Crane JP, Kopta MM. Genetic amniocentesis: impact of placental position upon the risk of pregnancy loss. Am J Obstet Gynecol 1984;150:813-816.

37. Giorlandino C, Mobili L, Bilancioni E, D'Alessio P, Carcioppolo $\mathrm{O}$, Gentili P, et al. Transplacental amniocentesis: is it really a higher-risk procedure? Prenat Diagn 1994;14:803-806.

38. Medda E, Donati S, Spinelli A, Di Renzo GC. Europop group genetic amniocentesis: a risk factor for preterm delivery? Eu J Obstetr and Gynecol Reprod Biol 2003;110:153-158.

39. Tongsong T, Wanapirak C, Sirivatanapa P, Piyamongkol W, Sirichotiyakul S, Yampochai A. Amniocentesis-related fetal loss: a cohort study. Obstet Gynecol 1998;92(1):64-67. 
40. Williamson RA, Varner MW, Grant SS. Reduction in amniocentesis risks using a real-time needle guide procedure. Obstet Gynecol 1985;65:751-755.

41. Therkelsen AJ, Rehder H. Intestinal atresia caused by second trimester amniocentesis. BJOG 1981;88:559-562.

42. Admoni MM, BenEzra D. Ocular trauma following amniocentesis as the cause of leukocoria. J Pediatr Ophthalmol Strab 1988;25:196-197.

43. Youroukos S, Papadelis F, Matsaniotis N. Porencephalic cysts after amniocentesis. Arch Dis Child 1980;55:814-815.

44. Stock RJ. Fetal death secondary to needle laceration during 2nd trimester amniocentesis: a case report. Prenat Diagn 1982;2:133-137.

45. Bruce S, Duffy JO, Wolf JE. Skin dimpling associated with midtrimester amniocentesis. Pediatr Dermatol 1984;2:140-142.

46. RaimerSS, Raimer BG. Needle puncture scars from midtrimester amniocentesis. Arch Dermatol 1984;120:1360-1362.

47. Finegan JK, Quarrington BJ, Hughes HE, Rudd NL, Stevens LJ, Weksberg R, Doran TA. Infant outcome following midtrimester amniocentesis: development and physical status at age 6 months. BJOG 1985;92:1015-1023.

48. BenEzra D, Sela M, Peer J. Bilateral anophthalmia and unilateral microphthalmia in two siblings. Ophthalmologica 1989;198:140-144.

49. Chong SKF, Levitt GA, Lawson J, Lloyd U, Newman CGH. Subarachnoid cyst with hydrocephalus-a complication of midtrimester amniocentesis. Prenatal Diagn 1989;9: 677-679.

50. Eller KM, Kuller JA. Porencephaly secondary to fetal trauma during amniocentesis. Obstet Gynecol 1995;85:865-867.

51. Raymond GV. Rare neurologic injury from amniocentesis. Birth Defects Res Clin Mol Teratol 2003;67:205-206.

52. An assessment of the hazards of amniocentesis: report of the MRC working party on amniocentesis. BJOG 1978; 85(suppl):1-41.

53. Clayton EM, Feldhaus WD, Whitacre FE. Fetal erythrosytes in maternal circulation of pregnant women. Obstet Gynecol 1964;23:915-919.

54. A Tabor, J Bang, B Norgaard-Pedersem. Fetomaternal haemorrhage associated with genetic amniocentesis: results of a randomized trial. Br J Obstet Gynecol 1987;94:528-535.

55. Murray JC, Karp LE, Williamson RA, Cheng EY, Luth DA. $\mathrm{Rh}$ isoimmunization related to amniocentesis. Am Journal of Medical Genetics 1983;16:527-534.

56. American College of Obstetricians and Gynecologists: Prevention of D Isoimmunization. ACOG Tech Bull No. 147, 1990.

57. WHO. Prevention of rhesus sensitization. WHO Technical Report Series 1971, No. 468.

58. Maiques V, Garcıa-Tejedor A, Perales A, Córdoba J, Esteban RJ. HIV detection in amniotic fluid samples amniocentesis can be performed in HIV pregnant women? Eur J Obstet Gynecol Reprod Biol 2003;108:137-141. 